\title{
A Clinical Study on Prevalence and Management of Hypertension in Adults
}

\author{
Ram Keshav Reddy ${ }^{1}$, S. Srinivas ${ }^{2}$ \\ ${ }^{1}$ Associate Professor, Department of Medicine, Kamineni Medical College, Narketpally Telangana, ${ }^{2}$ Associate Professor, Department of Medicine at Gems Medical \\ College Srikakulam Andhra Pradesh.
}

\section{Abstract}

Background: Hypertension is a major public health problem world-wide and in India. According to one survey the prevalence is $18 \%-22 \%$ in all the states of India Previously hypertension was common in urban areas and executives, but now it is increasing in rural population which may be due to sedentary life style increasing in obesity, changing food habits, stress and alcoholism. The prevalence in males is $22.95 \%$ and in females is $22.25 \%$. Hypertension is defined as persistently elevated blood pressure exceeding 140/90 mm of $\mathrm{Hg}$. Aim of the study: To assess the prevalence and management of hypertension. Subjects and Methods: We have conducted this study on 1900 adults. 290 were diagnosed as hypertensive. Results: We have examined 1900 adults out of these 1900 males were 1100 females were 800 . Blood pressure was recorded in 2 different occasions. All the guide lines by world health organization were followed out of these 290 males 195 , females were 85. Conclusion: Hypertension is gradually increasing in adult population and it is more prone to cause stroke and coronary artery disease. So screening programs are necessary in urban and rural areas of India.

Keywords: Hypertension, pre-hypertension, coronary artery disease, complications mortality, morbidity and strokes.

Corresponding Author: Dr. S. Srinivas, Associate Professor, Department of Medicine at Gems Medical College Srikakulam Andhra Pradesh.

Received: March 2018

Accepted: April 2018

\section{Introduction}

Hypertension is major public health problem in India and world-wide. HTN is defined as persistently elevated Systolic blood pressure more than $140 \mathrm{~mm}$ of $\mathrm{Hg}$ and Diastolic Blood pressure more than $90 \mathrm{~mm}$ of $\mathrm{Hg}$. It is one of the major risk factors for cardiovascular mortality which accounts for $25 \%$ to $50 \%$ of all deaths. ${ }^{[1]}$ There is also a direct relation between cardiovascular risk and blood pressure. The higher the blood pressure the higher the risk of stroke and coronary artery. ${ }^{[2]}$ But in individuals over age 50years the systolic pressure and pulse pressure are better predicators of complications than diastolic blood pressure. ${ }^{[3]}$ Adequate blood pressure control reduces the risk of acute coronary syndrome by $20 \%-25 \%$, stroke by $30-35 \%$; and heart failure by $50 \%$.

Stage I HTN is called when systolic blood pressure is between 140-150mm of $\mathrm{Hg}$ and Diastolic BP is between 90$99 \mathrm{~mm}$ of $\mathrm{Hg}$; and Stage II HTN is called when systolic BP is greater than $160 \mathrm{~mm}$ of $\mathrm{Hg}$ and Diastolic BP is greater than $100 \mathrm{~mm}$ of $\mathrm{Hg}{ }^{[4]}$ The uncontrolled HTN in public is increased between 1980 and 2008. High blood pressure is causing above 7.5 million deaths per year world-wide. ${ }^{[5]}$ Masked hypertension is where blood pressure is normal in the clinic but elevated at home. Guide lines from united kingdom suggests that ambulatory or home BP measurements should be used in preference to office based measurements in the diagnosis of hypertension. ${ }^{[6]}$
Data from Framingham cohost indicates that blood pressure bears a linear relationship with cardiovascular risk down to a systolic blood pressure of $115 \mathrm{~mm}$ of $\mathrm{Hg}$ based on these data, it has been suggested that individuals with blood pressure in the gray area of $120-139 / 80-89 \mathrm{~mm}$ of $\mathrm{Hg}$ be categorized as having prehypertension. Because pre HTN often develop into HTN (50\% of affected individuals do so within 4 years) Pre hypertension patients should be monitored annually adults. ${ }^{[7,8]}$

Essential HTN is the term applied to the $95 \%$ of hypertensive patients in which elevated blood pressure results from complex interactions between multiple genetic and environmental factors. Essential hypertension occurs in $10-15 \%$ white adults and $20-30 \%$ of black adults in the United-States. The onset is usually between 25 years to 50 years; it is un common before age 20years. ${ }^{\text {[9] }}$

\section{Subjects and Methods}

We have examined 1900 total no. of adults. Out of these 1900 males were 1100 and females were 800. Total no. of hypertensives are 290 and males were 195; females were 85. The maximum no. of hypertensives are in 30 of 40 years. We have recorded the blood pressure on the two separate occasions, by trained paramedical team. Those who are known hypertensives and chronic smokers and chronic alcoholics were excluded from this study. Blood pressure was recorded by sphygnomanometer by manually, in sitting 
position after giving sufficient time for relaxation subject with systolic blood pressure more than $140 \mathrm{~mm}$ of $\mathrm{Hg}$ and diastolic BP more than $90 \mathrm{~mm}$ of $\mathrm{Hg}$ were considered as hypertension.
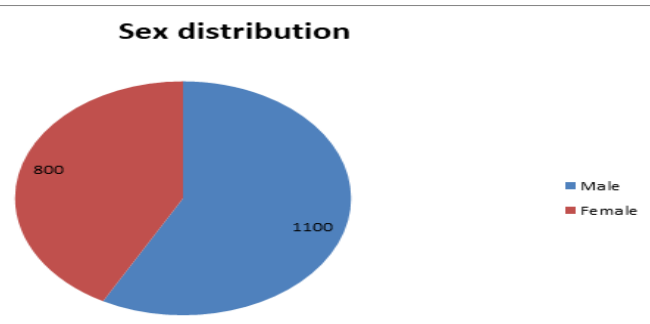

Figure 1: Sex distribution Total 1900

\section{Age distribution Females}

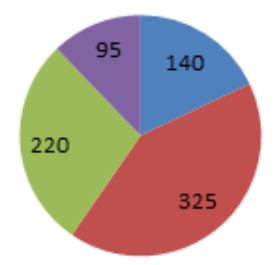

20-29 Yrs

- 30-39 Yrs

40-49 Yrs

E $>50$ Yrs

Figure 2: Age distribution Females

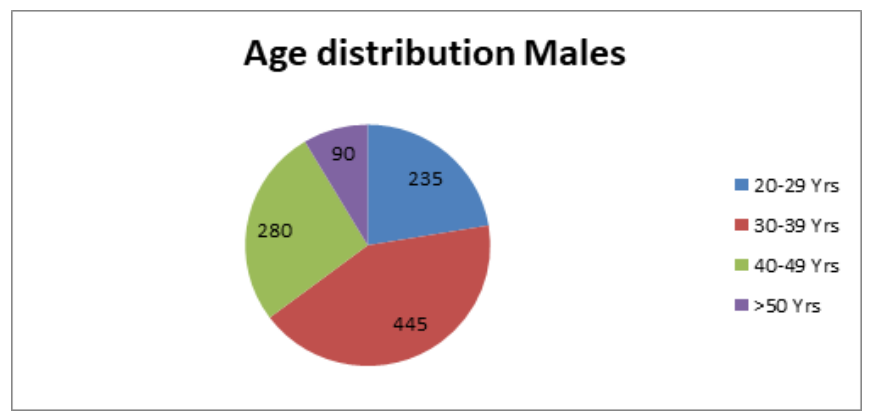

Figure 3: Age distribution Males

\section{Results}

We have examined the total no. of 1800 adults. Out of 1800 adults; 1100 are males and 700 are females. The total no. of hypertension are 290. Out of 290; males are 195 and females are 85 . The maximum age group is $30-39$ years.

Tables 1: Total No. of Subjects

\begin{tabular}{|l|l|l|}
\hline Males & Females & Total \\
\hline 1100 & 800 & 1900 \\
\hline
\end{tabular}

Tables 2: Total No. of Subjects with Hypertension

\begin{tabular}{|l|l|l|l|l|}
\hline Males & \% Percentage & Females & \% percentage & Total \\
\hline 195 & $15.26 \%$ & 85 & $12.97 \%$ & 290 \\
\hline
\end{tabular}

Tables 3: Total No. of Subjects Age Distribution

Tables 3: Total No. of Subjects Age Distribution
\begin{tabular}{|l|l|l|l|l|l|l|}
\hline S. no & Age & Males & \%Percentage & Females & \%Percentage & Total \\
\hline 1 & $20-29$ Yrs & 235 & $12.3 \%$ & 140 & $7.37 \%$ & $17.10 \%$ \\
\hline 2 & $30-39$ Yrs & 445 & $23.42 \%$ & 325 & 770 \\
\hline 3 & $40-49$ Yrs & 280 & $14.73 \%$ & 220 & $11.58 \%$ \\
\hline 4 & $>50$ Yrs & 90 & $7.01 \%$ & 95 & 500 & $7.12 \%$ \\
\hline
\end{tabular}

\section{Discussion}

Hypertension is major public health problem in India and world-wide. Studies shows that $50 \%$ of hypertensive patients were not diagnosed. Hypertension is asymptomatic in most of the patients.

The pathophysiology of hypertension includes over activation of sympathetic nervous system and renin. Angiotensin Aldosterone system, blunting of pressure nariuresis relationship, variation in cardiovascular and renal development and elevated intracellular sodium and calcium levels. ${ }^{[10]}$

Predisposing factors include obesity, sleep apnea, increased salt intake, excessive alcohol use smoking, Drugs like NASIDS and low potassium intake. Other causes of hypertension include chronic kidney disease, thyroid disease and coarctation of aorta. ${ }^{[11]}$

Alcohol can increase blood pressure probably by increasing plasma catecholamine's. NSAIDS produces increasing in blood pressure averaging $5 \mathrm{~mm}$ of $\mathrm{Hg}$.

Secondary hypertension should be suspected in patients in whom hypertension develops at an early age or after the age of 50 years and in those previously well controlled who become refrectory to treatment. Hypertension can be caused by mutation in single genes, inherited on $\mathrm{d}$ mendelian basis glucocorticoid remediable aldosteroneism is an autosomal dominant cause of early HTN with normal or high alchosternome and low renin levels.

The complications of hypertension include coronary artery disease, stroke, heart failure, kidney failure, and retinal damage. The awareness of hypertension in United States is $74 \%$ and in Australia is $64.5 \%$ where as in south east Asian countries it is very low because of low socio-economic and low literacy levels. ${ }^{[12]}$

In India more than $70 \%$ of all hypertensive patients are un aware according to national survey. ${ }^{[13]}$

In our study the prevalence of hypertension is $17.6 \%$ with slight predominance of male which is nears to other international and national studies. More than 1 Billion population is having blood pressure more than $140 / 90 \mathrm{~mm}$ of $\mathrm{Hg}$ world-wide and by 2025 it is going to increase up to 1.56 billion. $^{[14]}$

In our study the common age group is $30 \mathrm{yrs}$ to $39 \mathrm{yrs}$ the management includes, regular exercise, avoidence of smoking, alcohol, low salt intake and regular blood pressure checkups. According to survey conducted by Govt. of India, hypertension is present in $33 \%$ of adults who are more than 40 years of age. Several studies shows that only $50 \%$ of 
people with hypertension were diagnosed and half of those treated.

\section{Conclusion}

Hypertension is more prone to cause stroke including cerebral hemorrhage and infarction and coronary artery disease even though prevalence in high, still major built is still undiagnosed. So regular screening camps and health awareness programs are need by Govt. agencies and NGO's to reduce the mortality and morbidity.

\section{References}

1. Who 1980 bull. WHO 58;113-130.

2. Park and Park social and preventive medicine 2017 Edi.

3. Current medical diagnosis and treatment 2017 Edi.
4. Current medical diagnosis and treatment 2017 Edi.

5. Kearnay Pm Whellon.M Raynolds.K global burden of hypertension. Analysis of world-wide data Lancet 365-217-23.

6. Starn HR. The new hypertension guidelines. I. clin. Hypertension (Green which) 2013 oct.15 748-51.

7. Yoon SS et al. Trends in blood pressure among adults with HTN united states 2003 to 2012 HTN 2015 Jan 65(1) 54-61.

8. Yoon SS et al. Trends in blood pressure among adults with HTN united states 2003 to 2012 HTN 2015 Jan 65(1) 54-61.

9. Masserli FH. Et al. Essential hypertension. Lancet 2007 Aug 18370 (9587) 591-603.

10. Harrison's principles of internal medicine 19th Edi.

11. Mc. Cormark T Et al, management of hypertension in adults is primary case: NICE guidelines. Br. J. Gen. Pract. 2012 March:62.

12. Gupta R.et al gupta VP. Hypertension epidiomology in india. J hum. Hypertension July 1996 (7) 465-472.

13. Govt of India 2011 national health report. Ministry of health and family welfare

14. WHO report 2015.

Copyright: () the author(s), 2019. It is an open-access article distributed under the terms of the Creative Commons Attribution License (CC BY 4.0), which permits authors to retain ownership of the copyright for their content, and allow anyone to download, reuse, reprint, modify, distribute and/or copy the content as long as the original authors and source are cited.

How to cite this article: Reddy RK, Srinivas S. A Clinical Study on Prevalence and Management of Hypertension in Adults. Asian J. Med. Res. 2019;8(1):ME17-ME19.

DOI: dx.doi.org/10.21276/ajmr.2019.8.1.ME6

Source of Support: Nil, Conflict of Interest: None declared. 